4 Solonen, K A, Acta Orthopaedica Scandinavica, 1962, Suppl No 54.

5 Sunderland, S, Nerves and Nerve Injuries. Baltimore, Williams and Wilkins, 1968.

${ }^{6}$ Ewalt, J R, Randall, G C, and Morris, H, Psychosomatic Medicine, 1947, 9, 118.

7 Melzack, R, Advances in Neurology, 1974, 4, 319

${ }^{8}$ Head, H, and Holmes, G, Brain, 1911, 34, 102.

${ }^{9}$ Moore, D C, Regional Block: A Handbook for Use in the Clinical Practice of Medicine and Surgery, 4 th edn. Springfield, Illinois, Charles C Thomas, 1965.

${ }^{10}$ Shealy, C N, Advances in Neurology, 1974, 4, 775.

11 Gillis, L, British fournal of Surgery, 1964, 51, 87.

12 Ruch, T C, Advances in Neurology, 1974, 4, 329.

${ }_{13}$ Wilson, P R, et al, Mayo Clinic Proceedings, 1978, 53, 336.

${ }_{14}$ Cedercreutz, C, Acta Chirurgica Scandinavica, 1954, 107, 158

${ }^{15}$ Frazier, S H, Diseases of the Nervous System, 1966, 27, 441.

${ }^{16}$ Russell, W R, British Medical fournal, 1949, 1, 1024.

17 Livingston, W K, Archives of Surgery, 1938, 37, 353.

18 Wilson, D H, and Chang, A E, Confinia Neurologica, 1974, 36, 61.

${ }^{19}$ Elliott, F, Little, A, and Milbrandt, W, New England fournal of Medicine, $1976,295,678$

\section{Lymphocyte capping and carrier detection in Duchenne muscular dystrophy}

The most severe form of human muscular dystrophy, the Duchenne type, affects young boys and is known to be inherited by an X-linked recessive mechanism (as is the more benign and much less common Becker variety). Within the last 15 to 20 years many efforts have been made to attempt to identify women carriers of the genes responsible for these two conditions. If the Lyon hypothesis is accepted, then in the carrier female the X-chromosome carrying the Duchenne gene would be inactivated in about half of muscle nuclei, which would then be normal, while in the remaining half the normal chromosome would be inactivated, so that these nuclei would express the manifestations of the dystrophic gene. Some few women carriers do show minimal clinical evidence of muscular weakness (manifesting carriers), but this feature is not normally detectable unless precise quantitative methods of assessment of muscle power are used.

In patients with Duchenne type muscular dystrophy, the serum creatine kinase $(\mathrm{CK})$ activity is appreciably raised, especially in the early stages, and in 1959 Ebashi et al ${ }^{1}$ showed that the CK activity is raised in the serum of some female carriers. Subsequently this test has been recognised as the most effective means of identifying carriers, though only between $50 \%$ and $80 \%$ of definite carriers (who have an affected male child or sib and another affected male relative) show raised CK activity. In 1969 Emery $^{2}$ suggested that Bayesian probability methods be used to calculate a risk factor based primarily on the actual level of CK activity in the putative carrier and her mother. This technique has been widely used, and recent evidence suggests that an active carrier detection programme combined with genetic counselling has led to a reduction in the births of affected boys, though information is still being collected. Additional impetus has been given to carrier detection programmes since it became possible to sex the fetus by amniocentesis and then to recommend therapeutic abortion of males. More recently still, the introduction of fetoscopy combined with fetal blood sampling has raised the possibility that it may be feasible to recommend abortion only of presumptively affected males. ${ }^{3}$

Detection of carriers is especially important in the sisters of dystrophic boys, since if the mother of the affected boy carries the gene then each of her daughters has a $50 \%$ chance of being a carrier. Nevertheless, many patients with Duchenne muscular dystrophy are isolated cases, having been born into families with no history of the disease. These examples are presumed to result from mutation occurring either in the mother or in the maternal grandmother. If such a mutation occurred in only some of the mother's ovarian cells then her daughters would be unlikely to be carriers. In 1935 Haldane $^{4}$ estimated that if the incidence of a lethal X-linked disorder remains in equilibrium in a population then one-third of all cases must result from genetic mutation, and in 1970 Gardner-Medwin, ${ }^{5}$ following others, calculated that the mutation rate of this gene must be one of the highest recorded in human genetics. It has been estimated ${ }^{6}$ to lie between 4.6 and $9.4 \times 10^{-5}$.

Much work has recently been done to try to improve methods of carrier detection using techniques such as quantitative electromyography, muscle biopsy, ${ }^{78}$ and measurement of the incorporation of amino-acids into muscle polyribosomes in vitro. ${ }^{9}$ These methods have been tried as ways of identifying carriers in whom serum CK activity is normal.

More recent reports have suggested, firstly, that techniques based on the study of red blood cell membranes or of the white cells may be helpful, and, secondly, that the mutation rate in this condition may not be as high as has been thought. The abnormal release of cytoplasmic enzymes from the muscle cell into the serum seems to depend on changes in muscle membrane permeability. ${ }^{1011}$ Electron microscopic studies have shown that in patients with Duchenne dystrophy and in carriers there are also alterations in the surface membrane of the erythrocytes, and the biochemical behaviour of red cell membranes in blood samples obtained from patients with this disease and from carriers has been shown to be abnormal in several respects. ${ }^{12} 13$

These changes, as well as alterations in the shape of the erythrocytes, ${ }^{14}$ seem to be associated with altered membrane fluidity ${ }^{15} 16$ as shown by techniques such as electron spin resonance. Pickard et $a l^{17}$ have shown that these changes in membrane fluidity in B lymphocytes may influence the aggregation of fluorescent antigen-antibody complexes on their surface (the capping phenomenon). They found that in 61 patients with Duchenne, Becker, limb-girdle, facioscapulohumeral, and congenital muscular dystrophy there were fewer fluorescent lymphocytes that reached the capping stage, even when the total B lymphocyte count was normal. Capping was, however, normal in patients with myotonic dystrophy, motor neurone disease, polymyositis, and Kugelberg-Welander spinal muscular atrophy. In addition, just as Roses et al ${ }^{18}$ found biochemical abnormalities not only in erythrocyte ghosts in known female carriers of the gene but also in an unexpectedly high proportion of mothers of isolated cases, Pickard et al ${ }^{17}$ found a reduction in lymphocyte capping not only in known carriers but also in all but four mothers of isolated cases.

At first sight these findings, like those of Roses et al, , $^{18}$ suggest that many mothers of isolated cases-in whose sons the disease would be presumed to result from mutation-are in fact carriers of the gene. If confirmed, this finding must imply a mechanism such as selective fertilisation or a mutation rate several times higher in males than in females. The practical importance of these observations is obvious in relation to genetic counselling.

The findings reported by Pickard et $a l^{17}$ are important and deserve early replication. We must express caution, however, since many reports have failed to confirm all of the abnormalities in red cells reported in patients and carriers by Roses and his colleagues. ${ }^{18}$ Furthermore, there is evidence to indicate 
that if more precise ranges of values for serum creatine kinase activity in females of different ages are used, estimation of this enzyme in the serum may identify almost all the carriers if the test is carried out on young girls rather than adult women. ${ }^{19}$ Such a finding would be expected if the Lyon hypothesis is accepted: for the muscle nuclei containing the active dystrophic gene may be presumed to die off as the patient grows older, and serum CK activity does, indeed, seem to decline with age in carriers.

Observations which use serum CK activity as the sole means of carrier detection, and those based on estimation of serum pyruvate kinase, ${ }^{20}$ continue to support the traditional view that roughly one-third of all new cases of Duchenne dystrophy result from mutation. Further and more definitive studies are clearly needed; and certainly the lymphocyte capping phenomenon in the muscular dystrophies is worthy of further study. Whether it will prove to be a consistently reliable method of carrier detection remains to be seen.

${ }^{1}$ Ebashi, S, et al, fournal of Biochemistry (Tokyo), 1959, 46, 103.

${ }^{2}$ Emery, A E H, Scottish Medical fournal, 1969, 14, 335.
${ }^{3}$ Dubowitz, V, et al, Lancet, 1978, 1, 90.

${ }^{4}$ Haldane, J B S, fournal of Genetics, 1935, 31, 317.

${ }^{5}$ Gardner-Medwin, D, Journal of Medical Genetics, 1970, 7, 334.

${ }^{6}$ Kloepfer, H W, and Emery, A E H, in Disorders of Voluntary Muscle, 3rd edn, ed J N Walton, p 852. Edinburgh and London, Churchill Livingstone, 1974.

7 Walton, J N, and Gardner-Medwin, D, in Disorders of Voluntary Muscle, 3rd edn, ed J N Walton, p 561. Edinburgh and London, Churchill Livingstone, 1974.

${ }^{8}$ Dubowitz, V, Muscle Disorders in Childhood. Philadelphia, Saunders, 1978.

${ }^{9}$ Ionãsescu, V, Zellweger, H, and Conway, T W, Neurology (Minneapolis), 1971, 21, 703.

${ }^{10}$ Cullen, M J, and Fulthorpe, J J, Fournal of the Neurological Sciences, 1975, 24, 179.

${ }^{11}$ Mokri, B, and Engel, A G, Neurology (Minneapolis), 1975, 25, 1111.

12 Araki, S, and Mawatari, S, Archives of Neurology, 1971, 24, 187.

${ }^{13}$ Roses, A D, et al, New England fournal of Medicine, 1976, 294, 193.

${ }^{14}$ Matheson, D W, and Howland, J L, Science, 1973, 184, 165.

15 Cooper, R A, New England fournal of Medicine, 1977, 297, 371

${ }^{16}$ Butterfield, D A, Accounts of Chemical Research, 1977, 10, 111.

17 Pickard, N A, et al, New England fournal of Medicine, 1978, 299, 841.

${ }^{18}$ Roses, A D, et al, Annals of Neurology, 1977, 2, 271.

${ }^{19}$ Nicholson, G A, and Lane, R J M, Abstracts, IVth International Congress on Neuromuscular Diseases, No 487. Montreal, 1978.

${ }^{20}$ Percy, M E, et al, Abstracts, IVth International Congress on Neuromuscular Diseases, No 308. Montreal, 1978.

\section{Epidemiology and the Potteries}

North Staffordshire has a rich tradition of creative innovation. The area in which jasperware and English bone porcelain were first made has recently given birth to the second postgraduate medical school in England outside London. The University of Keele has appointed Professor E C Hutchinson as its first dean, with effect from 1 October. The school runs an extensive programme of postgraduate medical education and carries out research in its biochemical and medical engineering laboratories.

Last week a further innovation was made. A Centre for Research in Industrial and Community Health was opened with the object of "developing facilities for research in the field of medical epidemiology and preventive medicine in the Potteries." The project has been funded outside the National Health Service: the substantial sum necessary to provide the building and to finance the first research studies has been raised by private subscription. This suggests that the public is aware of the price that has been paid locally in terms of sickness and premature death for the development of the pottery industry and recognises that epidemiological research may lead to their prevention.

In a lecture inaugurating the centre Professor Donald Acheson suggested that epidemiology consisted of two elements-medical knowledge and the habit of counting people and relating them to populations. Many of its golden ideas had originated in clinical medicine, and there was good reason to suppose that many more opportunities of discovery awaited the observant clinician. Epidemiology was not a craft like ophthalmic surgery and best left to those specially trained and in constant practice. Rather it was an approach and method of thought which should pervade the whole of clinical medicine, helping not only in discovering causes but also in evaluating treatment and the achievement of a balanced view of the natural history of disease. Centres such as the one at Stoke would help to do that.

Professor Acheson also argued the case for a career structure for trained epidemiologists who did not wish to take on the important but largely administrative duties of community physicians and other specialists in community medicine. There should also be opportunities for people to combine epidemiology and clinical practice, both within university departments and outside them if they so wished. It was, he said, unfortunate that the specialty of community medicine (which controlled the only postgraduate training programmes which contained a formal element of epidemiology) offered at present little opportunity for the practice of epidemiology in its career posts and discouraged its members from undertaking part-time clinical practice.

Much of the impetus for the Stoke centre has, indeed, come from practising clinicians. The director, Dr Sam Cole, himself a specialist in respiratory medicine, hopes to make use of the remarkably stable population and the well-integrated health services to tackle both local and national problems; work has already begun on the relation of stomach cancer to pneumoconiosis and exposure to dust and on the epidemiology of tuberculosis. The combination of clinical and epidemiological studies being pioneered in the Potteries may set a new pattern for the future. 